Boglárka Weisz

\title{
GOSPODARSKA POZADINA KRALJEVSKE VLASTI U UGARSKOJ U 11. STOLJEĆU*
}

Boglárka Weisz

MTA BTK

Történettudományi Intézet

Budapest

\author{
UDK 929.52Arpadović \\ 338(439)“10"(091) \\ Prethodno priopćenje \\ Primljeno: 9.5.2018. \\ Prihvaćeno: 1.6.2020. \\ DOI: https://dx.doi.org/10.21857/y7v64t0zny
}

Studija analizira vladarske prihode Kraljevine Ugarske u 11. stoljeću, bilo da se radi o dohocima u naravi ili u novcu. Struktura vladarskih prihoda uspostavljena je već u doba Stjepana I., a tijekom 11. stoljeća mogu se primijetiti samo manje promjene, tako da studija analizira različite prihode isključivo kao dijelove jedinstvenog sustava: carine, naplata poreza, prihodi od kovanja novca i rudarenja plemenitih metala i soli. Studija završava ispitivanjem povremenih dohodaka na koje je vladar imao pravo, poput dijela novčanih kazni i darova.

Ključne riječi: dinastija Arpadovića, gospodarska povijest, kraljevski prihodi, povijest 11. stoljeća, porezi, carine, kovanje novca, rudarstvo

Ugarsko Kraljevstvo oslanjalo se na diferencirane prihode već u 11. stoljeću. Prihodi kraljevskog kućanstva u odnosima naturalne privrede u značajnoj su mjeri potjecali dijelom iz naturalnih podavanja stanovništva koje je živjelo na kraljevskim posjedima ili posjedima utvrda, odnosno njegove službe. Stanovništvo s kraljevskih posjeda podavanja je predavalo u upravni centar (lat. curia, mađ. udvár) najbližeg kraljevskog posjeda, gdje su boravili rizničari. Sve prinose skupljene na tim mjestima trošio je kralj obilazeći cijelu zemlju sa svojom brojnom svitom. ${ }^{1}$ Vrijednost prihoda u naravi bilo je toliko teško odrediti da čak ni u popisu prihoda Bele III. (1172. - 1196.) s kraja 12. stoljeća nema brojčane procjene, već je samo zapisano da

\footnotetext{
* Autorica je voditeljica Skupine za istraživanje mađarske srednjovjekovne gospodarske povijesti Lendület ("Zamah") Centra za filozofska i humanistička istraživanja Mađarske akademije znanosti (MTA BTK).

1 György Györffy, A “lovagszent” uralkodása (1077-1095) [Vladavina "viteškog sveca”], Történelmi Szemle, sv. 20, Budapest 1977., str. 542.
} 
"narod zemlje u potpunosti opskrbljuje kralja hranom". ${ }^{2}$ Međutim, njihovu važnost dobro pokazuje činjenica da se i u donacijama kleru - uz donacije u zemljištu, vinogradima i šumama te ribarskim mjestima - redom pojavljuje to stanovništvo i od njega pobirana naturalna podavanja, uz carine, o kojima će podrobnije biti riječi u nastavku. Tako, primjerice, 120 kućanstava u mjestu Ártánd u županiji Bihar, koje je 1075. darovano samostanu u Garamszentbenedeku (slov. Hronský Beňadik, njem. Sankt Benedikt), godišnje je moralo dati 12 svinja od pet godina i 12 akova meda, a pored toga su ljeti i zimi morali vršiti službu s dva konja. ${ }^{3}$ Iznimku čini samo darovnica iz Tihanya iz 1055., u kojoj je Andrija I. (1046. - 1060.), pored navedenog, naredio davanje 50 ždrijebaca iz kraljevskog $\mathrm{krda}^{4}{ }^{4}$ a prema jednoj povelji iz 1148 . Ladislav I. (1077. - 1095.) je darovao kaptolu u Óbudi (Stari Budim) 360 pensa godišnje iz kraljevske komore (de sua camera). ${ }^{5} \mathrm{U}$ listinama privilegija krajem 11 . stoljeća pojavljuju se donacije vezane za isporuku soli, a privilegije vezane za oslobođenje od poreza ili predavanje kraljevskog poreza tek krajem 12. stoljeća. Sve to dobro pokazuje da su vladari u 11. stoljeću od svih novčanih kraljevskih prihoda jedino prihode od carina smatrali stalnim izvorom prihoda koji je omogućavao darovanje.

Legenda o svetom Gerardu (mađ. Gellért, odgajatelj sina kralja Stjepana I. Ugarskog, kanoniziran 1093.) izravno ukazuje na carine koje su se pojavile za vladavine prvoga kralja, Stjepana (1000. - 1038.), kada izvještava da je Ajtony na rijeci Maros postavio ubirače carina, koji carine čak i kraljevsku sol. ${ }^{6}$ Carina koju je Stjepan I. ubirao posredno se, no izričito, pojavljuje i u zakonima kralja Kolomana, po kojima oni koji nešto od vlastitih i domaćih proizvoda prodaju na sajmu prema zakonima svetog Stjepana moraju platiti carinu. ${ }^{7}$ Povrh toga, uz ime Stjepana I. tradicija veže darovanje sedamnaestog dijela carine. ${ }^{8}$ Oslobođenje od plaćanja carina prema neautentičnoj

2 Et per hec omnia populus terre regi facit victum plenarium. János Barta Ifj. - Gábor Barta, III. Béla jövedelmei (Megjegyzések a középkori uralkodóink bevételeiről) [Prihodi Bele III. (Bilješke o prihodima naših srednjovjekovnih vladara], Századok, sv. 127, Budapest 1993., str. 444.

3 Diplomata Hungariae antiquissima accedunt epistolae et acta ad historiam Hungariae pertinentia I. (ab anno 1000 usque ad annum 1131), prir. György Györffy et al., Budapest 1992. (dalje: DHA), str. 215.

4 DHA, str. 151.

5 Budapest történetének okleveles emlékei I. Monumenta diplomatica civitatis Budapest I, Zbirku Dezse Csánkya dopunio i pripremio za tisk Albert Gárdonyi, Budapest 1936. (dalje: BTOE 1), str. 3.

6 Scriptores rerum Hungaricarum, sv. 1-2, prir. Emericus Szentpétery, Budapest 1937. - 1938. (dalje: SRH), sv. 2, str. 489-490.

7 The Laws of the Medieval Kingdom of Hungary I. 1000-1301, prir. János M. Bak - György Bónis - James Ross Sweeney, Idyllwild, California 1999. (u nastavku: The Laws), str. 28. (ch. 34).

8 Az Árpád-kori magyar történet bizánci forrásai. Fontes byzantini historiae hungaricae aevo ducum et regum ex stirpe Árpád descendentium, prir. Gyula Moravcsik, Budapest 1988., str 80. Szántó (ž. Fejér); 1001: DHA, str. 41; Pozsony (ž. Pozsony); +1015.: DHA, str. 76; Pécsvárad (ž. Baranya);+1019.: DHA, str. 91; Csány (ž. Zala), Csurgó (ž. Somogy), Kolon (ž. Zala); +1037.: DHA, str. 118; Komárom (ž. Komárom), Árpás (ž. Győr), Bát (ž. Hont), Szil (ž. Sopron); 1109: DHA, str. 379; Szigetfő (ž. Fejér); 9. rujna 1261.: Árpádkori oklevelek a Heves Megyei Levéltárban. Diplomata Aetatis Arpadiana in archivo comitatus Hevesiensis conservata, prir. Erzsébet Látkóczki Kondorné, Eger 1997., str. 27-28; Lúc (ž. Zemplén), Örvény (ž. Heves), Szentmária (ž. Zemplén); +18. ožujka 1263.: Monumenta Vaticana historiam regni hungarae illustrantia. Vatikáni magyar okirattár, sv. 1/4, Budapest 2000., str. 265; Tata (ž. Komárom); 31. kolovoza 1271.: Codex 
povelji darovao je već i Stjepan I., ${ }^{9}$ kao što je oslobođenje od carine građana Stolnog Biograda tradicija također vezala za kralja Stjepana I. ${ }^{10}$ Sajamska carina pojavila se na sajmovima u županijskim i crkvenim središtima, a prva mjesta ubiranja carine nastala su duž trgovačkih putova. ${ }^{11}$ Ladislav I. nastojao je osigurati ubiranje sajamskih carina, što pokazuje i odredba koja je trgovačku djelatnost dopuštala samo na sajmovima. Propisivala je da se ugovor o kupoprodaji sklopi pred sucem, carinikom i svjedocima. ${ }^{12}$ Carine su do Kolomanova doba postale sigurnim izvorom prihoda, što pokazuje i činjenica da je kralj zakonom naložio ubiranje desetine i od carina. ${ }^{13}$ Štoviše, za njegove vladavine došlo je i do reforme carina, u kojoj je naložio da trgovci na duge relacije plaćaju dvostruku vrijednost stare carine. ${ }^{14}$ Vladar je vanjsku trgovinu opteretio ne samo višim carinama nego je osigurao i nadzor kraljevskog dvora: oni koji su htjeli napustiti zemlju, morali su imati i kraljev pečat i pečat carinika pograničnog župana (comes confinii). ${ }^{15}$ Popis prihoda Bele III. s kraja 12. stoljeća među sedam glavnih stavki prihoda vladara spominje carine, prihod od splavarenja te sajmova. ${ }^{16}$

Uz ubiranje carine, za vladavine svetog Stjepana pojavilo se i ubiranje poreza. ${ }^{17}$ Sveti Gellért piše da "oni koji vladaju samo zato da imaju naslov, proždru narod, utjeraju poreze (tributa) [...] nisu kraljevi, već razaratelji". ${ }^{18}$ Premda Gellért u svojim djelima nije kritizirao Stjepana, ${ }_{19}^{19}$ ta izjava nedvosmisleno ukazuje na to da je jedna od popratnih pojava vladanja bilo ubiranje poreza, to jest, da je već prvi vladar iz

diplomaticus Hungariae ecclesiasticus ac civilis, sv. 1-11, prir. Georgii Fejér, Budae 1829. - 1844. (u nastavku: CDH), 7/2, str. 151; Trencsén (ž. Trencsén); 1400.: Zsigmondkori Oklevéltár, 2/1, no. 10, prir. Elemér Mályusz. Budapest 1956.; Föveny (ž. Fejér).

9 +1254.: Rerum Hungaricarum monumenta Arpadiana, prir. Stephanus Ladislaus Endlicher, Sangalli 1849., str. 484-487.

10 O privilegiji Stolnog Biograda u najnovije vrijeme vidi: Attila Zsoldos - Tibor Neumann, Székesfehérvár középkori kiváltságai [Srednjovjekovne povlastice Stolnog Biograda], Székesfehérvár 2010.

11 Boglárka Weisz, A királyketteje és az ispán harmada. Vámok és vámszedés Magyarországon a középkor elsô felében [Kraljevska polovina i županska trećina. Carine u Ugarskoj u prvoj polovici srednjeg vijeka], Budapest 2013. 10-14.

12 The Laws, str. 14 (ch. 7).

13 The Laws, str. 27 (ch. 25).

14 The Laws, str. 28 (ch. 33).

15 The Laws, str. 32 (ch. 82).

16 Idem habet de pedaiis et passagiis et mercatis seu foris, que omnia sua sunt, triginta milla marcarum (Barta Barta, III. Béla jövedelmei, str. 444).

17 Usp. György Györffy, István király és müve [Kralj Stjepan i njegovo djelo], Budapest 1983., str. 340-347.

18 Catalogus fontium historie hungaricae, prir. Albinus Franciscus Gombos, sv. 1-3, Budapest 1937. - 1938. (u nastavku: CFHH), sv. 2, str. 1028.

19 U stručnoj literaturi pojavljuje se ime i Petra i Samuela Abe, usp. József Gerics, Az 1040-es évek magyar történetére vonatkozó egyes források kritikája [Kritika nekih izvora o ugarskoj povijesti u četrdesetim godinama 11. stoljeća], Magyar Könyoszemle, sv. 98, Budapest 1982., str. 300-306; József Gerics, A Pseudo-Isodorus-gyűjtemény szövegei és a 11. század első felének magyarországi társadalmi ideológiája. (Válasz Kristó Gyulának) [Tekstovi Pseudo-Izodorove zbirke i ugarska društvena ideologija prve polovice 11. stoljeća. (Odgovor Gyuli Kristóu)], Magyar Könyvszemle, sv. 101, Budapest 1985., str. 165, 169; Gyula Kristó, Gellért püspök, valamint Péter és Aba Sámuel királyok viszonyának kérdéséhez (Válasz Gerics Józsefnek) [O pitanju odnosa biskupa Gerarda i kraljeva Petra i Samuela Abe (odgovor Józsefu Gericsu)], Magyar Könyvszemle, sv. 101, Budapest 1985., str. 175-179. 
obitelji Arpadovića uveo oporezivanje. Vladari nakon svetog Stjepana, Petar Orseolo (1038. - 1041. / 1044. - 1046.) i Samuel Aba (1041. - 1044.) također su ubirali poreze. Prema Ilustriranoj kronici (Képes Krónika) Samuel Aba je izbrisao odluke i namete (exactiones) Petra Orseola. ${ }^{20}$ Prema Györgyju Györffyju i Józsefu Gericsu, Petar je spram Stjepana nametnuo nove poreze, ${ }^{21}$ a prema Iloni Bolla i Gyuli Kristóu, Petar je ubirao samo poreze koje je nametnuo Stjepan, čak i ako je to činio na uređeniji način. ${ }^{22}$

Jedan je od tih poreza vjerojatno bio porez koji kasniji izvori nazivaju slobodnim denarima (liberi denarii) ili denarima slobodnjaka (libertini denarii), ${ }^{23}$ koji su kolokvijalno nazivali dimnicom (vulgo fumarii). ${ }^{24}$ György Györffy je daću koja se plaćala u naravi smatrao pretečom dimnice, a uvođenje dimnice smjestio je u 1020. godinu, u razdoblje nakon učvršćivanja ugarsko-bizantskih veza. Po njegovu mišljenju Stjepan I. je uveo dimnicu pod grčkim utjecajem, naime, riječ kapnos, to jest samostalna proizvodna jedinica, koja se pojavljuje u povelji o osnivanju iz Veszprémvölgya, služila je kao osnova oporezivanja te se na tom temelju određivao porez (kapnikon). ${ }^{25}$ Mjere svetog Stjepana Koloman je modernizirao u skladu s odnosima njegova doba, ponegdje olabavivši "okov lanca zakona", a ponegdje postroživši prijašnje propise. ${ }^{26}$ Koloman je u svom I. zakoniku odredio da se "onih 8 denara koje se ubiralo od svakog pojedinog slobodnjaka odsada neće ubirati". ${ }^{27}$ Kako je Alberik, koji je sastavio pojedine točke, $u$ prologu zakonika izjavio da odredba obuhvaća odluke sjednice $u$ Tarcalu, na kojoj su okupljeni pregledali zakone svetog Stjepana, ${ }^{28}$ moramo zaključiti da su se spomenuti denari, ubirani od slobodnjaka, čak i ako se iznos s vremenom

20 SRH 1, str. 325-326. Zakone koje je donio Petar, odnosno njihovo brisanje za Abine vladavine spominju i Annales Altahenses maiores, no ne i poreze, vidi CFHH 1, str. 94.

21 Györffy, István király és müve, str. 341; Gerics, Az 1040-es évek, str. 300-306; Gerics, A Pseudo-Isodorus-gyüjtemény, str. 169.

22 Ilona Bolla, A jogilag egységes jobbágyosztály kialakulása Magyarországon [Formiranje pravno ujednačene klase kmetova u Ugarskoj], Budapest 1983., str. 35; Kristó, Gellért püspök, str. 177.

${ }^{23}$ Porez poznat kao denar slobodnjaka izazvao je žustre rasprave među povjesničarima, koji su s jedne strane raspravljali o tome je li to kraljevski ili vlastelinski porez, a s druge strane vodili diskusije oko pojma liberi, vidi: László Erdélyi, Az első állami egyenes adó elmélete [Teorija prvog državnog izravnog poreza], Kolozsvár 1912., str. 14-25, 28-44, 51-65; Bálint Hóman, Adó vagy földbér?, Budapest 1913.; Ferenc Eckhart, Erdélyi László: Az első állami egyenes adó elmélete, Kolozsvár 1912., Századok, sv. 2, Budapest 1913., str. 439-442; Károly Tagányi, Válasz dr. Erdélyi László megjegyzéseire [Odgovor na napomene dr. Lászla Erdélyja], Történelmi Szemle, sv. 3, Budapest 1914., str. 435-451; János Varga, Az Árpád-kor szabaddénárosai. Romány Pál köszöntésére [Denari slobodnjaka doba Arpadovića. U pozdrav Pálu Rományu], Agrártörténeti Szemle, sv. 47, Budapest 2006., str. 1-55. Ostalu literaturu vidi u potonjoj studiji.

24 1225.: Dedimus igitur ipsis libertinos denarios, qui vulgo fumarii vocantur (Sopron vármegye története. Oklevéltár I. 1156-1411, prir. Imre Nagy, Sopron 1889., str. 16); +1230.: libertinos denarios, qui vulgo fumarii vocantur (Árpádkori új okmánytár, sv. 1, prir. Gusztáv Wenzel, Pest 1860., str. 270).

25 Usp. Györffy, István király és műve, str. 342. Mađarski izvori nikada ne nazivaju taj porez kapnikonom, no u stručnoj se literaturi uz kapnikon susrećemo s izrazom dima ili denara slobodnjaka, vidi: Rózsa Zsótér, Kapnikon, u: Korai magyar történeti lexikon (9-14. század) [Leksikon rane ugarske povijesti (9.-14. st.)], prir. Gyula Kristó et al., Budapest 1994., str. 325.

26 The Laws, str. 24-25 (Prolog), 28. (ch. 34).

27 Denarii VIII, qui de liberis singulis colligebantur, amodo non accipiantur (The Laws, str. 29 (ch. 45)).

28 The Laws, str. 24. 
promijenio, ubirali još od doba svetog Stjepana. Kako su se na temelju zakona svetog Stjepana slobodnima (liber) smatrali svi koji nisu bili servi, ${ }^{29}$ vjerojatno se taj porez odnosio na velikaše jednako kao i na siromašne slobodne seljake. Najkasnije se za vladavine svetog Ladislava može opaziti diferencijacija pojma liber pojavom razlikovanja plemića (nobiles) i slobodnjaka (liberi) koji su služili Crkvama. ${ }^{30}$ Ne znamo je li odvajanje gornjeg sloja libera išlo ruku pod ruku s brisanjem obveze plaćanja poreza ubiranog od slobodnih, ili se, kao što to daju naslutiti Kolomanovi zakoni, oslobođenje od poreza na plemiće odnosilo tek od Kolomanove vladavine. Međutim, odredba nije značila brisanje poreza, već je promijenila krug poreznih obveznika.

Može se pretpostaviti da su pored denara slobodnjaka postojale i druge vrste poreza, kao što su pondus, zvan "nehezék" (mađ. "uteg, teg"), koji se u kasnijim izvorima pojavljuje uz denar slobodnjaka, ili census, kojim se otplaćivala radna obveza.

Najvažniji izvor prihoda kraljevske riznice prema popisu prihoda Bele III. bila je dobit od kovanja novca. U Ugarskoj se u vrijeme Arpadovića kovanje novca smatralo kraljevskim monopolom, te su kovati novac mogli, osim vladara, samo kneževi koji su imali područnu vlast. Izdavanje prvoga ugarskog novca uglavnom je služilo samo u svrhu prestiža, no ugarsko gospodarstvo i društvo u tijeku preobrazbe ubrzo su zahtijevali masovno izdavanje samostalnoga domaćeg platežnog sredstva. Početak redovita kovanja novca možemo smjestiti u razdoblje nakon $1015 .{ }^{31}$ Nakon pokretanja redovita kovanja novca valjalo je povesti brigu i o rasprostiranju toga novca u zemlji, što se vjerojatno odvijalo na sajmovima, u županijskim središtima. Ladislav bi svake dvije godine izdao nov novac, a u drugoj polovini vladavine kovao je već izuzetno kvalitetne kovanice. Nastojao je ugarski fiskalni sustav uklopiti u europski sustav platnog prometa, pa se prilagodio vodećoj valuti tog doba: njegovih je četrdeset težih srebrnjaka (denara) vrijedilo jedan bizantski zlatnik (solidus). To su nazivali pensom ili bizantiusom kralja Ladislava. ${ }^{32}$

U kraljevskoj kovnici novca u doba Karolinga, u novac se kovalo zlato i srebro koje su donosili pojedinci. Na kovanje novca prema zakonskim bi propisima odbili određeni postotak kovanog novca na ime troškova riznice kao zakonsku pristojbu na kovanje novca, a ostatak bi se uručio donositelju sirovine. ${ }^{33}$ To je vjerojatno bio običaj i u Ugarskoj tijekom 11. stoljeća, smatramo li vjerodostojnim izvješće o zakonu rabina Jehude ben Meir ha-Kohena iz Mainza iz sredine 11. stoljeća, prema kojem je jedan ugarski Židov zatražio i dobio dozvolu od ugarske kraljice da mu upravitelj kovanja novca iskuje sitni novac u vrijednosti od 100 funti od njegova vlastita

29 Ilona Bolla, A jogilag egységes jobbágyságról Magyarországon [O pravno ujednačenom kmetstvu u Ugarskoj], Budapest 1998., str. 15-20.

30 Bolla, A jogilag egységes jobbágyságról, str. 22-27.

31 Usp. László Kovács, A kora Árpád-kori pénzverésről [O ranom kovanju novca u doba Arpadovića], Budapest 1997., str. 278-279.

32 Györffy, A “lovagszent” uralkodása, str. 540.

33 Bálint Hóman, Magyar pénztörténet 1000-1325 [Povijest ugarskog novca 1000. - 1325.], Budapest 1916., str. 410-411. 
srebra. ${ }^{34}$ Dobit je od kovanja novca dvojaka: pristojba za kovanje novca i zamjena novca. Do prve se moglo doći na dva načina. Jednostavnije rješenje bilo je to da se određeni postotak kovana novca odbije na ime troškova riznice. Druga je mogućnost bila ta da se od jedinice težine iskuje ne zakonski propisani, već ponešto veći broj komada novca, čime se smanji udio plemenitog metala u novcu. Međutim, pri zamjeni se novca računalo kao da se od jedne jedinice težine iskovao propisani, to jest manji broj komada novca s većim udjelom plemenitog metala: razlika između propisanog i iskovanog novca činila je pristojbu za kovanje novca. Pristojba za kovanje novca postala je stalnim prihodom kad se pokrenulo periodično kovanje novca. Zamjena starih kovanica započela je za vrijeme Salomona (1063. - 1074.), no bila je rijetka i neredovita. ${ }^{35}$ Periodička zamjena novca vjerojatno je započela za vladavine Ladislava I., no njezina se učestalost ne može točno odrediti, dok je u stručnoj literaturi prihvaćeno da se izdavanje novog novca odvijalo svake dvije godine. ${ }^{36}$ Nakon izdavanja novog novca, pri stavljanju novca u promet, to jest pri zamjeni novca riznica je ostvarivala određenu dobit. No, riznica je ostvarivala dobit ne samo periodičnom zamjenom novca, već i zamjenom novca u drugim slučajevima, kao kad bi mijenjali strani novac, nekovani plemeniti metal ili novac prethodnih vladara.

Dakako, kovanje novca ne bi funkcioniralo bez rudnika plemenitih kovina, koji su također povećavali kraljevske prihode; doduše, dobit se od njih u nadolazećim stoljećima višestruko povećala otkrivanjem sve novijih rudnika i produbljivanjem iskopa. O rudnicima iz 11. stoljeća nemamo pisanih izvora, možemo se osloniti samo na arheološke nalaze i toponime. U 12. stoljeću Abu Hamid al-Garnati govoreći o bogatstvu zemlje navodi: "njihove planine skrivaju mnogo srebra i zlata". ${ }^{37}$ Možemo pretpostaviti da se iskapanje srebra u okolici Selmecbánya (danas Banská Štiavnica, Slovačka) odvijalo već u 11. stoljeću, no tada još iskapanjem blizu površine tla, ${ }^{38}$ kao što je ispiranje zlata u potocima i rijekama - na što među ostalim ukazuje i naziv rijeke Aranyos (mađ. "pozlaćena, zlatna", rum. Arieș) - također bilo poznat postupak.

Pored rudnika plemenitih kovina kralj je zacijelo vukao korist i iz rudnika soli u Erdelju. Legenda o svetom Gellértu, kad ukazuje na to da je knez Ajtony ubirao carinu od kraljevske soli prenošene kroz Maros, ${ }^{39}$ ujedno dokazuje da su ti rudnici već od ranih vremena spadali pod nadležnost kralja. ${ }^{40}$ Carina na sol jedna je od naj-

34 Géza Komoróczy, Források és dokumentumok a zsidók történetéhez Magyarországon: Szöveggyújtemény [Izvori i dokumenti za povijest Židova u Ugarskoj: Zbirka tekstova], Budapest 2005., no. 3.

35 Kovács, A kora Árpád-kori pénzverésről, str. 284, 291.

36 Hóman, Magyar pénztörténet, str. 229.

37 Abu-Hámid al-Garnáti utazása Kelet-és Közép-Európában 1131-1153 [Putovanje Abu-Hamida al-Garnatija u istočnu i srednju Europu 1131.-1153.], prir. O. G. Bolsakov - A. L. Mongajt, Budapest 1985., str. 58.

38 Pouzdano možemo računati s tim da su do provale Tatara bila dva središta iskapanja srebra, u Banskoj Štiavnici (mađ. Selmecbány) i transilvanskoj Radni (mađ. Besztercevidék), no podatci o njima pojavljuju s tek od 13. stoljeća.

39 SRH 2, str. 489-490.

40 Podrobnije vidi Boglárka Weisz, Megjegyzések az Árpád-kori sóvámolás és -kereskedelem történetéhez [Bilješke o povijesti carinjenja soli i trgovine u razdoblju Arpadovića]. Acta Historica, sv. 125, Budapest 2007., str. 43-57. 
ranijih vrsta carina, što dokazuje i činjenica da su u određivanju carinskih stavki, za razliku od drugih carinskih stavki, primjenjivali decimalni sustav. ${ }^{41}$ Trgovinu solju vezanu za doba svetog Stjepana spominje - neautentična - povelja o osnivanju opatije u Pécsváradu iz 1015., prema kojoj je opatija imala pravo vaditi sol bez ikakvih ograničenja i isporučivati je bez carinjenja. ${ }^{42}$ Prema povelji o osnivanju opatije u Garamszentbenedeku (danas Hronský Beňadik, Slovačka) iz 1075. opatija je od Gejze I. dobila polovinu kraljevskog dijela carine soli, to jest trećinu carine u mjestu Aranyos (danas Unirea, Rumunjska) pored Torde (danas Turda, Rumunjska). ${ }^{43}$ Prema darovnici, pak, opatiji u Bakonybélu iz doba svetog Ladislava, opatija je 1086. dobila dvadeset četiri kućanstava (mansio) obvezanih na proizvodnju blokova soli i rudnik soli, odnosno tri broda kojima su sol tri puta godišnje mogli otpremiti u samostan bez carinjenja. ${ }^{44}$ Premda je u sve tri povelje nastale $\mathrm{u} 11$. stoljeću dio teksta o soli naknadno dodan, one ipak dobro svjedoče o vladarskom monopolu soli. ${ }^{45}$ Međutim, pravo na sol opatije u Bakonybélu potvrđuje i drugi izvor, po kojem je Ladislav I. 1092. dao opatiji dvadeset četiri mansio, koji su bili dužni isporučivati opatiji oko 3000 blokova soli godišnje. ${ }^{46}$ Međutim, župan udvornika (comes udvornicorum) Opus htio je opatiji oduzeti njezine podložnike u vrijeme vladavine Stjepana II. (1116. - 1131.), no u sporu pred Stjepanom II., a potom Belom II. (1131. - 1141.) opatija je 1131. obranila svoja prava. ${ }^{47}$ Prema Beatrix Romhányi, Opus je u tom predmetu postupio kao kraljevski dužnosnik, a u njegove zadaće spadala je provjera i revizija kraljevskih prihoda, kako nešto od njih ne bi nezakonito dospjelo u strane ruke. Stoga sudjelovanje opatija u transportu soli vjerojatno nije bilo uobičajeno u prvom desetljeću 12. stoljeća. Istodobno priznaje da je privilegij transporta soli opatija u Bakonybélu vjerojatno dobila još prije $1131 .^{48}$ Po našem mišljenju ništa ne isključuje mogućnost da je upravo Ladislav I. bio taj koji je opatiji darovao brodove za prijevoz soli, stoga iz

1 Usp. Weisz, Királyketteje, str. 34.

42 +1015.: DHA, str. 72-80. Isprava je nastala dvadesetih godina 13. stoljeća (DHA, str. 63-71).

43 DHA, str. 213-217. Budući da papa Inocent III. (1198. - 1216.) u ispravi od 15. svibnja 1209., u kojoj je potvrdio dobra samostana u Garamszentbenedeku, nije spomenuo carinu (Codex diplomaticus et epistolaris Slovaciae, sv. 1, prir. Richard Marsina, Bratislava 1971. [dalje: CDES 1], str. 118-119) te da je nakon provale Tatara samostan doživio poteškoće glede utjerivanja carine, tekst koji ukazuje na carinu soli u Aranyosu vjerojatno je u ispravu iz 1075. umetnut između 1209. i 1256.

44 DHA, str. 255. Ta se odredba nalazi u interpoliranom dijelu nastalom u prvoj polovici 12. stoljeća (DHA, str. 248-250).

45 Prema mišljenju uvriježenom u stručnoj literaturi kraljevski se monopol soli počeo pojavljivati tek u 12. - 13. stoljeću. Usp. Oszkár Paulinyi, A sóregálé kialakulása Magyarországon [Formiranje regalnog prava na sol u Ugarskoj], Századok, sv. 57, Budapest 1924., str. 627-647; András Kubinyi, Königliches Salzmonopol und die Städte des Königreichs Ungarn im Mittelalter, u: Stadt und Salz, ur. W. Rausch, Linz - Donau 1988., str. 213-294.

46 A pannonhalmi Szent-Bendek-rend története 8 [Povijest pannonhalmskog benediktinskog reda], Sörös Pongrác, A bakonybéli apátság története [Povijest opatije Bakonybél], Budapest 1903., str. 272.

47 Na ist. mj.

48 Beatrix Romhányi, A beregi egyezmény és a magyarországi sókereskedelem az Árpád-korban [Bereški dogovor i trgovina ugarskom solju u doba Arpadovića], u: Válság-kereskedelem [Trgovina krize], ur. György Kövér - Ágnes Pogány - Boglárka Weisz, Budapest 2016., str. 271. 
povelje nastale prije 1086., premda je interpolirana, vjerojatno samo dio o brodovima za prijevoz soli potječe iz vremena nakon doba Ladislava I.

Vladari su već od doba svetog Stjepana imali prihode i od kazni. Budući da nije stalan prihod, nije uveden u popis prihoda Bele III. U zakonima Stjepana I., prema paragrafu o umorstvu za umorstvo s namjerom mora se platiti 110 zlatnika, od kojih 50 u kraljevsku riznicu, 50 rođacima, a 10 sucima i suradnicima. ${ }^{49}$ Novčana se kazna pojavljuje i u sanctio formulama povelja: componat centum libras auri optimi medium camere nostre ac medium prefato monasterio ${ }^{50}$ András Kubinyi postavio je tezu da je propisivanje novčane kazne vjerojatno bilo utjecaj carskih povelja. ${ }^{51}$ Formula koja se pojavljuje i u mađarskim izvorima doista je bila rasprostranjena u Svetom Rimskom Carstvu, ${ }^{52}$ no njezini korijeni zapravo sežu u rimsko doba..$^{53} \mathrm{U}$ Ugarskom

49 The Laws, str. 4 (ch. 14).

50 DHA, str. 40. Vidi još primjerice 1009.: octo millia librarum auri cocti sciat se conpositurum medietatem camere nostre et medietatem prelocuto Sancti Mychaelis Wespremiensi ecclesie (DHA, str. 53); 1009.: conponat centum libras auri optimi medium camere nostre ac medium prefato episcopatui (DHA, str. 58); +1015.: componat centum libras auri optimi mediam camere regie, medietatem vero abbati (DHA, str. 80); +1019.: conponat quinquaginta libras auri optimi medium camere nostre ac medium prefato monasterio (DHA, str. 92); +1024.: conponatque centum libras auri purissimi, medium camere nostre ac medium prefato monasterio (DHA, str. 102); +1037.: componat XX marcas purissimi auri, medium camere regie mediumque abbati et rectoribus sepedicti monasterii (DHA, str. 119); 1075.: insuper solvat purissimi auri libras mille, medietatem regie camere et medietatem predicto monasterio Sancti Benedicti (DHA, str. 218).

51 Andras Kubinyi, Királyi kancellária és udvari kápolna Magyarországon a XII. század közepén [Kraljevska kancelarija i dvorska kapela u Ugarskoj u sredini 12. stoljeća], Levéltári Közlemények, sv. 46, Budapest 1975., str. 77, 154.

52 Primjerice 951.: poena multetur auri optimi librarum centum, medietatem kamere nostre et medietatem ipsi cui molestia inlata fuerit inferendam constituimus (Monumenta Germaniae Historica. Die Urkunden der Deutschen Könige und Kaiser, sv. 1-3, Hannover 1879. - 1903. (dalje: MGH DD KK) 1, str. 216); 962.: sciat se compositurum auri optimi libras centum medietatem kamere nostre et medietatem pretaxato episcopo vel cui illata fuerit controversia (MGH DD KK 1, str. 356); 983.: sciat se compositurum auri optimi libras centum medietatem kamere nostre et medietatem predictis canonicis (MGH DD KK 2, str. 312); 998.: sciat se compositurum auri optimi libras mille medietatem kamere nostre et medietatem abbati ipsius monastarii qui tunc temporis fuerit (MGH DD KK 2, str. 733); 1001.: componat atque persolvat auri optimi libras mille medietatem kamere nostre et medietatem sepe dicto episcopo Odelrico suisque successoribus (MGH DD KK 2, str. 826); 1013.: senciat se compositurum centum libras obtimi auri medietatem kamere nostre et medietatem predicto archiepiscopo (Joseph Dessaix, La Savoie historique, pittoresque, statistique et biographique, Genève 1980., str. 157-158); 1036.: componat auri purissimi libras mille medietatem kamere nostre et prefato monasterio alteram (MGH DD KK 3, str. 309); 1141.: XXXta libras auri purissimi conponat, quarum partem dimidiam camere nostre, reliquam vero prefato Ekkeberto [...] persolvat (Niederösterreichisches Urkundenbuch, sv. 2/1, prir. Günter Marian et al., St. Pölten 2013., str. 259); 1174.: Quod qui fecerit meiestatis reus centum libras auri purissimi pro pena componat, dimidium imperiali camere et reliquum Imolensi civitati (Annali Bolognesi 2/2, Bassano 1789., str. 49). Usp. Edward Baumstark, Kameralistische Enciklopediae. Handbuch der Kammeralwissenschaften und ihrer Literatur für Rechts- und Verwaltungs-Beamte, Landstaende, Gemeinde-, Raethe und Kameral-Candidaten, Heidelberg - Leipzig 1835., str. 5; Hans Hirsch, Aufsätze zur mittelalterlichen Urkundenforschung, Darmstadt 1965., str. 117-120, 130-131, 142-143, 186-188.

53 Primjerice, qui presumpserit in ultionem sue temeritatis libras mille auri purissimi pro pena componat quotiescumque presumpserit contraire dimidium imperiali camere reliquum civitati Bononie integre persolvatur (Annali Bolognesi, sv. 3/2, Bassano 1795., str. 490). Usp. Fritz Boye, Über die Poenformeln in den Urkunden des frühen Mittelalters, Archiv für Urkundenforschung, sv. 7, Leipzig 1918., str. 77-148, ovdje str. 109-110. Nastanak formule kažnjavanja može se dovesti u vezu s rimskim pravom, Hans Peter 
Kraljevstvu formula se - ne uzimajući u obzir manje promjene - može uočiti do 13. stoljeća, ${ }^{54}$ no na Zapadu je ostala u upotrebi i u kasnijim razdobljima. ${ }^{55}$ Zahvaljujući tomu ona se tek za Žigmundove vladavine ponovno pojavljuje, ${ }^{56}$ doduše, samo u slučajevima kad vladar prepisuje povelju nekoga prijašnjeg njemačko-rimskog cara, koja također sadrži navedenu formulu. ${ }^{57} \mathrm{U}$ mađarskim izvorima - kao i na Zapadu ${ }^{58}$ - u navedenoj se formuli umjesto izraza camera povremeno javlja i fiscus..$^{59}$ To je bila komora iz koje je sveti Ladislav izdao 360 pensa crkvi u Óbudi (Starom Budimu). ${ }^{60}$

Sveti Gellért je u djelu Deliberatio pisao kako je "nečuvena hereza društva to da traže povrat milodara koji su po kršćanskom običaju dani za duše pokojnika", to jest "premda smo imenom biskupi, nametnuli su nam porez". ${ }^{61}$ Sporno je pitanje je li se Gellértova opaska odnosila na Petra Orseola ${ }^{62}$ ili Samuela Abu, ${ }^{63}$ no u svakom se slučaju dobro uočava da su vladari nakon Stjepana tražili nove izvore prihoda za pokrivanje svojih izdataka.

Glöckner, Cogitationis poenam nemo patitur (D. 48.19.18.): zu den Anfüngen einer Versuchslehre in der Jurisprudenz der Glossatoren, Frankfurt am Main 1989., str. 213.

54 1217.: quinquaginta marcas fisco regio et alias quinquaginta episcopof [...] persolvat (CDH 3/1, str. 213).

55 Primjerice 1248.: mille marcas auri pro pena se compositurum cognoscat, medietate nostre camere, reliqua passis iniuriam applicando (Historia diplomatica Friderici Secundi sive constitutiones, privilegia, mandata, instrumenta quae supersunt istius Imperatoris et filiorum eius. Accedunt epistolae paparum et documenta varium, sv. 7/2, prir. Jean-Louis-Alphonse Huillard-Bréholles, Paris 1861., str. 669); 1311.: Si quis autem hoc violare presumpserit centum libras puri auri componat medietatem camere nostre reliquam medietatem passis iniuriam persolvat (Documenti illustrativi per la storia della Cittá e Campagne di Milano. Del Conte Giorgio Giulini. Dal Secolo VIII al XV, sv. 7, Milano 1857.); 1364.: poenam mille marcharum auri puri, quarum medietatem aerarii nostri seu fisci imperialis, reliquam vero medietatem camere episcopalis usibus applicari statuimus (Monumenta Aquensia ad excellentissimus et reveretissimum virum Josephum Antonium Corte primo Aquensem nunc Monregalensem episcopum, sv. 1, prir. Joannes Baptista Moriondus, Taurini 1789., str. 331); 1513.: poenam 50 marcharum auri puri [...], quarum medietatem fisci nostri caesarei aerario, reliquam vero partem januensibus ipsis volumus applicari (Imperii germinici ius ac possessio in Genua Ligustica eiusque dicionibus, prir. Heinrich Christian von Senckenberg, Hannover 1751., str. 284).

56 Primjerice 1424.: penam mille librarum auri puri, cuius medietatem fisci nostri regalis, reliquam vero partem sepedictis Ottoni et Casmiro, ducibus Stetinensibus et heredum suorum usibus applicari decernimus (http:// www.ruegenwalde.com/literatur/heinemann/teil-9.htm, preuzeto 26. lipnja 2017.).

57 Usp. 1357.: penam mille librarum auri puri, cuius medietatem fisci nostri imperialis, reliquam vero sepedicti ducis Stetynensis et heredum suorum usibus applicari decernimus (http://www.ruegenwalde.com/literatur/ heinemann/teil-6.htm, preuzeto 26. lipnja 2017.).

58 Uza sve navedeno upotrebljavali su i izraz scrinium, primjerice 1024.: auri purissimi C libras componat et medietatem ipsis liberis hominibus, quibus iniuria facta fuerit, et medietatem scriniis imperatoris persolvat (MGH DD KK 3, str. 689); 1115.: auri optimi libras centum componat, medietatem scriniis nostris et medietatem prelibato Ottoni (Codex Chronologico-Diplomaticus episcopatus Ratisbonensis, sv. 1, Thomas Ried, Ratisbonae 1816., str. 176).

59 1057.: insuper pene centum librarum auri subiacet, huius pene medietas regio fisco inferatur, ac alia pars dimidia ecclesie Beati Petri [...] persolvatur (DHA, str. 162).

60 BTOE 1, str. 3.

61 Béla Karácsonyi - László Szekfü, Deliberatio Gerardi Moresanae aecclesiae episcopi Svpra Hymnum trium Pverorum. Elmélkedés Gellért, a marosi egyház püspöke a három fiú himnuszáról, Budapest - Szeged 1999.

62 Usp. Gerics, Az 1040-es évek, str. 300-306; Gerics, A Pseudo-Isodorus-gyüjtemény, str. 165, 169.

63 Usp. Kristó, Gellért püspök, str. 175-179. 
Upitno je možemo li među navedene ubrojiti dvadesetinu i stotinu crkvene desetine. Desetinu koja se plaćala Crkvi svojim je zakonima uveo sveti Stjepan, ${ }^{64}$ a Koloman je odredio da se desetina plaća i od kraljevskih poreza i carina (tributum et vectigalium). ${ }^{65}$ Početak nametanja dvadesetine nije nam poznat, no znamo da je već Bela II. u prvoj polovini 12. stoljeća kraljevsku dvadesetinu biskupije u Vácu darovao crkvi svete Margarete u Dömösu. ${ }^{66}$ I Zlatna bula iz 1231. spominje dvadesetinu kao prihod koji pripada kralju odavna (ab antiquo). ${ }^{67}$ Prema jednoj povelji koju je Karlo I. (Karlo Robert, 1301. - 1342.) izdao 1319., negdašnji sveti kraljevi i prelati zemlje odredili su da dvadeseti i stoti dio crkvene desetine pripadne kralju, a preostali se dio također kraljevskom moći i ovlastima treba utjerati za Crkvu. ${ }^{68}$ Međutim, osim vladara dvadesetinu ili stotinu desetine posebnim kraljevskim donacijama mogli su dobiti i baruni kraljevstva, župani i podžupani, ${ }^{69}$ no u tom su slučaju morali imati toliku moć i ovlasti da mogu utjerati i preostali dio desetine. ${ }^{70}$ Sve to, pak, ukazuje na to da su i dvadesetina i stotina, $s$ jedne strane, bile utvrđeni dio crkvene desetine, dakle ne prihod dodan na desetinu, $\mathrm{i}, \mathrm{s}$ druge strane, da se ubiranje desetine provodilo $\mathrm{s}$ pomoću vladara, odnosno vladareva aparata, te da se utvrđeni dio crkvene desetine vjerojatno uživao zauzvrat za potonje. Na to ukazuje povelja iz 1190., u kojoj vladar, premda zabranjuje palatinu prihod dvadesetine a županu stotine crkvene desetine, određuje i da ubirači desetine mogu zatražiti pomoć palatinovih ili županovih ljudi. ${ }^{71}$ Intervenciju kraljevskog miljea potkrepljuju i zakoni Andrije III. (1290. - 1301.), po kojima je ubirač desetine ubiranje provodio sa županovim čovjekom (cum homine

64 Si cui deus decem dederit in anno, decimam deo det (The Laws, str. 11. (ch. 20)).

65 The Laws, str. 26 (ch. 25).

${ }_{66}$ De episcopatu Waciensi vicesima regis ecclesie sancte Margarete data est in primo anno regni regis Bele (CDES 1, str. 75).

67 The Laws, str. 40 (ch. 16).

68 [...] olim sancti reges et progenitores nostri et prelati venerabiles regni huius sancte et provide statuerunt, ut ex decimis ecclesiasticis partem vicesimam et centesimam habeat regia magnitudo et relique partes non per ecclesiasticas sentencia, set potestate et auctoritate regia pro ecclesiis exigantur (Codex diplomaticus regni Croatiae, Dalmatiae et Slavoniae, sv. 8, prir. Tadija Smičiklas et al., Zagreb 1910. (dalje: CD 8), str. 530).

69 Dvadesetina je vjerojatno povećavala prihode palatina a stotina župana: Item, nec comes palatinus vicesimam, nec comes parochianus centesimam in decimis ecclesiarum omnium habere debeat, nec quisquam alius hominum praetextu alicuius adiutoriis in decimis exigendis, preexcellentiae, vel comitatus, penitus nullius fastigii nomine, aliquid de ipsis decimis ecclesiae diminuere, et sibi modo aliquo vel occasione nacta usurpare presumpmat (CDH 2, str. 256).

$70[. .$.$] quod barones regni, comites, vicecomites vel quecumque alie private persone, qui ex speciali donacione regia$ aut ex consvetudine sui officii vel honoris ex decimis ecclesiasticis porciones percipiunt antedictas, tante debeant esse auctoritatis et potencie, quod ad solvendas partes reliquas decimarum sine sentenciis ecclesiasticis populum compellere valeant per auctoritatem regiam et potenciam temporalem (CD 8, str. 530).

${ }^{71}$ Item precipimus omnes officiales Ecclesie, qui decimatores vocantur, si voluerint, cum homine Palatini, vel Comitis Parochyani dicare decimas possint (CDH 2, str. 255). Kada 1320. Karlo Robert osigura privilegije hospitesima koji se nastanjuju u Bártfi (slov. Bardejov) te naređuje da se jedna polovina desetine njihovih prinosa da župniku, a druga polovina kralju (CDH 8/2, str. 253), što dobro pokazuje da podjela desetine koja bi se plaćala crkvi nije nepoznata praksa ni u kasnijim razdobljima. 
parochialis comitis). ${ }^{72}$ Prema zakoniku svetog Ladislava ubiranje desetine provodio je biskupski pristav (pristaldus episcopi), dok su kraljevski i županov pristav (pristaldus regis et comitis) po pitanju desetine djelovali samo u dvojbenim slučajevima. ${ }^{73}$ Sve to, pak, ukazuje na to da je u ubiranju desetine s vremenom došlo do promjene, a dvadesetina je uvedena vjerojatno tek poslije, nakon vladavine Ladislava I.

Popis prihoda Bele III., povrh navedenih, kao izvor prihoda spominje i darove župana, prihod koji je po svemu sudeći bio na raspolaganju vladarima već u 11. stoljeću, te je osim kralju pripadao i kraljici i hercezima. Također u ovaj izvor prihoda možemo uvrstiti i sve darove koje su vladar i njegova obitelj dobivali preko poslanika ili osobno - od stranih vladara ili pape, ili od osoba koje su u prolasku kroz zemlju uživali i kraljevo gostoprimstvo. Kad je saski grof Vilim krenuo u Ugarsku kako bi svoju nevjestu Sofiju, kćer Bele I., poveo "razmećući se velikim bogatstvom", ${ }^{74}$ vjerojatno je ponio i predmete velike vrijednosti koje je namijenio kralju kao dar. ${ }^{75}$ Kad je Boleslav III. stigao u Ugarsku i pošao na hodočašće do svetog Egidija (opatija svetog Egidija u Somogyváru) i svetog Stjepana (kraljeva groba u Stolnom Biogradu), odnosno kad se susreo i s kraljem Kolomanom, prema poljskoj je kronici Boleslav III. darovao crkvama zlato i plašteve,${ }^{76}$ te premda ne spominje darove kralju, možemo biti sigurni u to da Boleslav ni Kolomana nije izostavio s popisa osoba kojima mora darovati.

U 11. stoljeću financijska je pozadina kraljevske vlasti u prvom redu potjecala od carina, poreza, kazni te ponajviše od kovanja novca, dok je prihod od rudnika plemenitih kovina daleko zaostajao za prihodima koji će oni donositi u kasnijim stoljećima. Suprotno tomu, rad rudnika soli vjerojatno je bio mnogo intenzivniji, te su i prihodi koji od njih potječu značajno povećavali prihode riznice. Vladari su trošili dobra koja su proizveli podložnici. Kraljevske donacije odnosile su se na te prihode u naravi, na carine i, u manjem dijelu, na rudnike soli kao najpouzdanije izvore stalnih prihoda. Povrh navedenog, vrijednost darova koje su vladari dobivali od domaćih i stranih osoba vjerojatno je bila značajna već u 11. stoljeću.

Preveli: Lea Kovács i dr. György Lukács B.

\footnotetext{
The Laws, str. 64. (ch. 14).

The Laws, str. 61 (ch. 40).

Monumenta Germaniae Historica. Scriptores Rerum Germanicarum 38, str. 79.

75 No, Vilim je na putu preminuo i nije stigao u Ugarsku.

76 CFHH 1, str. 491.
} 
Weisz Boglárka

\section{The Economic Background of the Royal Rule in Hungary in the Eleventh Century}

\section{Summary}

In the eleventh century, the royal finances of the Kingdom of Hungary relied on differentiated revenues. In the conditions of primarily natural economy, the income of the royal household to a significant extent came from the dues paid in kind and services of the dependent groups of people living in the court and the castle-estates.

The structure of the financial background of the eleventh century royal power was formed already during the reign of the first king, Stephen I. From the population was levied a tax, which was in later sources called by the terms of the "money of the free" (liberi denarii) or "money of the freemen" (libertini denarii), and was colloquially called as "money of a hearth" (vulgo fumarii). In addition to the "money of the free," the existence of other types of taxes can also be assumed, so in later sources, in addition to the "money of the free," the pondus is noted, which was called "heavy," or the census paid for the redemption of labour service. Travelers and merchants in the country were had to pay customs. The nonpermanent income of the ruler included fines and gifts received from the comites/ispánok, foreign rulers, or the pope.

The main source of income of the Royal Treasury According to Béla III's income list, was a profit from minting. The first emission of money probably was made more from the reasons of prestige, but the regular minting can be traced back to 1015 . The profit from minting was twofold: there was a fee on minting and a currency exchange fee. The latter became a permanent income with the start of periodic coinage, which could have started during the reign of Ladislas I. Minting would not been possible without mining of noble ore, which also increased royal incomes, though the income from this fell far short of the revenues from this item in later centuries. In addition to ore mining, the king certainly benefited also from the Transylvanian salt mining.

Key words: the Árpád dynasty, economic history, royal revenues, the eleventh-century history, taxes, tolls, minting, mining 